Resectron

\title{
Adrenal steroidogenesis following prenatal dexamethasone exposure in the spiny mouse
}

\author{
Tracey A Quinn', Udani Ratnayake ${ }^{2}$, Margie Castillo-Melendez ${ }^{1}$, Karen M Moritz ${ }^{3}$, \\ Hayley Dickinson, ${ }^{1, *}$ and David W Walker ${ }^{1,4, *}$ \\ ${ }^{1}$ Monash Institute of Medical Research, The Ritchie Centre, Monash University, 27-31 Wright Street, Clayton, \\ Victoria 3168, Australia \\ ${ }^{2}$ The Florey Institute of Neuroscience and Mental Health, University of Melbourne, Melbourne, Victoria 3010, \\ Australia \\ ${ }^{3}$ School of Biomedical Sciences, The University of Queensland, St Lucia, Queensland 4072, Australia \\ ${ }^{4}$ Department of Obstetrics and Gynaecology, Monash Medical Centre, Monash University, Clayton, \\ Victoria 3168, Australia \\ *(H Dickinson and D W Walker are equal senior authors)
}

Correspondence should be addressed to D W Walker Email david.walker@monash.edu

\begin{abstract}
Antenatal stress disturbs the development of the fetal hypothalamic-pituitary-adrenal axis and adrenal steroidogenesis. We investigated the effect of brief maternal exposure to high glucocorticoids (dexamethasone (DEX)) at mid- and late-pregnancy on adrenal structure and production of steroids in spiny mouse. Pregnant spiny mice were treated for $60 \mathrm{~h}$ with $125 \mu \mathrm{g} / \mathrm{kg}$ DEX or saline s.c. by osmotic minipump at day $20(0.5)$ or $30(0.75)$ of gestation. Immunohistochemical expression of steroidogenic acute regulatory-protein (StAR), 3 $\beta$-hydroxysteroid dehydrogenase (3ßHSD), 17-hydroxylase, 17-20lyase (P450C17), and cytochromeb5 (CYTB5) was determined in adrenals on postnatal $(P)$ day $170 \pm 20$. DHEA, testosterone, and cortisol were measured by RIA. Maternal DEX at 20 days significantly reduced the expression of STAR, P450C17 (CYP17A1), and CYTB5 in the adrenal zona reticularis (ZR) of adult offspring, with greater change in male vs female offspring $(P<0.05)$. Plasma DHEA was decreased in male offspring from DEX-treated $(6.84 \pm 1.24 \mathrm{ng} / \mathrm{ml})$ vs saline-treated $(13 \pm 0.06 \mathrm{ng} / \mathrm{ml} ; P=0.01)$ dams, and the DHEA:cortisol ratio was lower in males $(P<0.05)$. Testosterone levels increased in male offspring from DEX $(266.03 \pm 50.75 \mathrm{pg} / \mathrm{ml})$ vs saline $(83.47 \pm 32.3 \mathrm{pg} / \mathrm{ml}, P<0.05)$-treated dams. DEX treatment at 0.75 gestation had no significant effect on any parameters measured. This study shows that brief exposure to excess glucocorticoid has long-term impacts on the ZR and adrenal steroidogenesis, affecting the secretion of DHEA and testosterone in male offspring, an effect produced at 0.5 but not at 0.75 gestation. DHEA is important for brain development, and its suppression in adult life might contribute to the neurobehavioral pathologies that can arise after illness and stress during pregnancy.
\end{abstract}

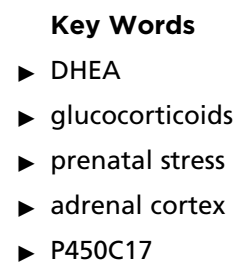

Journal of Endocrinology (2014) 221, 347-362

\section{Introduction}

Epidemiological data suggests that fetal development is affected by a number of stresses during gestation, which can lead to alterations in the regulation of stress-sensitive physiology into adult life (Adams et al. 1993, Brosnan 2001, Goodyer et al. 2001, Cotter \& Pariante 2002, Anisman \& Merali 2003, Barker 2004). This developmental 
'programing' of physiological, endocrine, and behavioral functions during pregnancy is thought to be mediated by maternal glucocorticoids. At high concentrations, the free fraction of circulating maternal glucocorticoids can cross the placental and fetal blood-brain barriers (Zarrow et al. 1970, Herbert 1998), where they affect fetal hypothalamic-pituitary-adrenal (HPA) activity and modify the development of several organ systems, particularly the brain. One outcome of maternal physical or psychological illness during pregnancy is an increased risk of neurodevelopmental alterations in the fetus, which can lead to several psychiatric illnesses postnatally, including mood disorders and schizophrenia (Hammen et al. 1987, Mednick et al. 1988, Larsson et al. 2005).

A large body of evidence suggests that chronic maternal stress may increase the incidence of preterm birth, developmental delays, and psychiatric and behavioral abnormalities in children. Because increased secretion of cortisol is a common feature of illness and stress, this steroid has become a candidate as a 'programing factor' in prenatal stress. However, other adrenal steroids may be involved. The androgen DHEA is particularly interesting because of its anti-glucocorticoid actions in the brain (Kimonides et al. 1998, Cardounel et al. 1999, Kimonides et al. 1999, Kurata et al. 2004), and because adrenal secretion has been shown to be altered in several disease states and psychopathologies (Goodyer et al. 2001). For example, decreased plasma DHEA and/or its sulfated derivative DHEAS occurs in patients with rheumatoid arthritis, coronary artery disease, anorexia nervosa, anxiety, depression, and obsessive compulsive disorder (Barrett-Connor et al. 1986, Wilder 1996, Goodyer et al. 1998, Gordon et al. 1999, Wolkowitz \& Reus 2000, Harris et al. 2001, van Niekerk et al. 2001, Bigos et al. 2009). HPA axis dysregulation has been described for psychosis in general, and for schizophrenia in particular (Cotter \& Pariante 2002), and includes increased basal cortisol secretion (Ryan et al. 2004), increased adrenocorticotropic hormone (ACTH)/cortisol responsiveness to the dexamethasone (DEX)/corticotrophic-releasing hormone challenge test (Lammers et al. 1995), and increased plasma DHEA concentrations in severely psychotic male subjects and medicated patients with chronic schizophrenia (Oades \& Schepker 1994, di Michele et al. 2005).

ACTH is the endogenous adrenal secretagogue for both cortisol and DHEA (Kalimi et al. 1994), for both of which $17 \alpha$-hydroxypregnenolone is the direct precursor. DHEA synthesis in the adrenal gland and brain is mediated by the enzyme P450c17, in association with the hemoprotein cytochromeb5 (CYTB5; Compagnone \& Mellon
1998, Mapes et al. 1999, Zwain \& Yen 1999, Tagawa et al. 2006). In the brain, this important androgen is a potent anti-glucocorticoid (Kalimi et al. 1994, Kimonides et al. 1999), which may be highly significant in the context of prenatal stress and ensuing brain pathology in humans. DHEA has been shown to protect hippocampal neurons against the neurotoxic effects of both glutamate analogs and glucocorticoids, where it is thought to modulate neuronal survival through stress-activated protein kinaserelated intracellular pathways (Kimonides et al. 1998).

The relationship between DHEA and cortisol in the developing fetus has been difficult to examine in conventional laboratory rodents, as rat and mouse adrenal glands do not express P450c17, and adrenal DHEA production is insignificant at any stage of life (Van Weerden et al. 1992). Moreover, the major adrenal glucocorticoid in these species is corticosterone (Van Weerden et al. 1992, Ishimura \& Fujita 1997). The spiny mouse (Acomys cahirinus) has a relatively long gestation (38-39 days) (Brunjes et al. 1989), and in contrast to other rodents their adrenal glands express both P450C17 (CYP17A1) and accessory hemoprotein CYTB5, and secrete both cortisol and DHEA from at least mid-gestation (Quinn et al. 2013). The aim of this study was to determine the long-term consequences of a brief exposure to maternally administered glucocorticoid, as a model of transient stress in pregnancy, on the synthesis of DHEA and cortisol in adult offspring. A low dose of the synthetic glucocorticoid DEX was used in this study to model a transient rise in maternal glucocorticoid. Importantly, DEX is a synthetic glucocorticoid that binds preferentially to the glucocorticoid receptor, and not the mineralocorticoid receptor (Welberg \& Seckl 2001), and therefore mimics the effects of endogenous glucocorticoids acting through the glucocorticoid receptor. This model has previously been shown to lead to reduced nephron numbers, altered renal gene expression in the fetal spiny mouse (Dickinson \& Walker 2007a), and altered male sexual behavior in laboratory rat, both outcomes of which are also observed after maternal stress caused by immobilization and crowding stress (Holson et al. 1995, Hayashi et al. 1998). The timing of the excess glucocorticoid exposure was chosen to occur either just before or just after differentiation of the major steroidogenic zones of the adrenal cortex, the evidence of which was shown previously (Quinn et al. 2013), and is extended in the present study by examining the expression and localization of STAR, P450C17, CYTB5, and 3 $\beta$-hydroxysteroid dehydrogenase (3BHSD) in the spiny mouse adrenal gland at both 20 and 30 days of gestation ( 0.5 and 0.75 term

Published by Bioscientifica Ltd 
respectively). Finally, as previous studies have found that the outcomes of adverse in utero conditions with respect to increased glucocorticoids can be more prominent in male than in female offspring (Aiken \& Ozanne 2013), and the incidence of neurological illness, such as schizophrenia, is also greater in males (Johnston \& File 1991, Iacono \& Beiser 1992), we also determined the sex difference in response to this maternal glucocorticoid treatment.

\section{Materials and methods}

\section{Animals}

All experimental procedures were approved by School of Biomedical Sciences, Animal Ethics Committee, Monash University and were conducted in accordance with the Australian Code of Practice for the Care and Use of Animals for Scientific Purposes. Spiny mice were bred and housed as described previously (Dickinson \& Walker 2007b).

\section{DEX administration}

Osmotic micro pumps (Azlet, model 1003D) were implanted s.c. in pregnant spiny mice at either 20 days of gestation (12 dams) or 30 days of gestation (12 dams), as described previously (Dickinson et al. 2007), and they received either DEX (Sigma-Aldrich; $125 \mu \mathrm{g} / \mathrm{kg}$ body weight; $n=6$ dams at 20 days and $n=6$ dams at 30 days), or saline ( $n=6$ dams at 20 days and $n=6$ dams at 30 days) administered over $60 \mathrm{~h}$. Untreated (control group) dams ( $n=6$ dams at 20 days and $n=6$ dams at 30 days) received no surgical treatment. Each pregnant spiny mouse was then allowed to deliver naturally.

\section{Sample collection}

Pups were weaned at 40 days of postnatal age and housed with the same sex groups of up to four animals until they reached $170 \pm 20$ days of age, when they were killed and blood and tissue collected. Male $(n=6)$ and female $(n=6)$ spiny mice at $170 \pm 20$ days of postnatal age of each treatment (control, saline, and DEX) and fetal age (20 vs 30 days of gestation) group were killed by decapitation and blood was collected from the trunk vessels. Plasma was obtained by centrifugation $\left(5 \mathrm{~min}\right.$ at $3000 \mathrm{~g}, 4^{\circ} \mathrm{C}$ ) and stored at $-20^{\circ} \mathrm{C}$ before DHEA, cortisol, and testosterone RIA. Owing to restrictions in plasma volume, control (untreated) group plasma was not available for testosterone RIA. All adrenal glands were collected through a midline abdominal incision. Both adrenal glands were excised, and the left gland was weighed and immersed in $4 \%$ paraformaldehyde for $24 \mathrm{~h}$ before being processed and paraffin embedded for histology and immunohistochemistry (IHC). Right adrenal glands were weighed and frozen at $-80{ }^{\circ} \mathrm{C}$ for immunoblot analysis ( $n=2$ per sex). Adrenal glands were also collected from untreated fetal male and female spiny mice at 20 days of gestation $(n=6)$ and 30 days of gestation $(n=11)$, and processed as mentioned earlier. Blood and tissue collection always occurred between 1030 and $1130 \mathrm{~h}$.

\section{Hormone assays}

Cortisol was extracted from plasma using dichloromethane, and total plasma cortisol was measured by RIA as described previously (Bocking et al. 1986) using cortisol as standard (H-4001, Sigma Chemical Company). The values obtained by RIA were corrected for the extraction recovery (mean recovery, 74.6\%). The intra-assay coefficient of variation (CV) was $2.1 \%$ at $1.5 \pm 0.26 \mathrm{ng} / \mathrm{ml}$ and $7.7 \%$ at $64.5 \pm 2.09 \mathrm{ng} / \mathrm{ml}$. The assay sensitivity was $0.37 \mathrm{ng} / \mathrm{ml}$. DHEA was measured in spiny mouse plasma using a commercially available RIA kit according to manufacturer's instructions (DSL8900, Beckman Coulter, Brea, CA, USA). The cross-reactivity of the antisera used in the assay was determined by the manufacturer and was $<0.75 \%$ with other structurally similar steroids. For plasma, the intra-assay $\mathrm{CV}$ was $2.9 \%$ at $2.5 \pm 0.75 \mathrm{ng} / \mathrm{ml}$ and $5.3 \%$ at $7.5 \pm 2.25 \mathrm{ng} / \mathrm{ml}$. The assay sensitivity was $0.2 \mathrm{ng} / \mathrm{ml}$. Plasma testosterone concentration was measured using a commercially available RIA kit according to manufacturer's instructions (IM1119, Immunotech, Marseilles, France). The cross-reactivity of the antisera used in the assay was determined by the manufacturer and was $<0.75 \%$ with other structurally similar steroids. The assay sensitivity for serum testosterone was $15.6 \mathrm{pg} / \mathrm{ml}$. The intra-assay CV was $8.0 \%$.

\section{Hemotoxylin and eosin staining}

Hemotoxylin and eosin staining was carried out to assess the cell morphology of adrenal glands. Paraffin-embedded sections $(5 \mu \mathrm{m})$ were stained in alum hemotoxylin for $5 \mathrm{~min}$ and then rinsed in running distilled water. Sections were then differentiated with $0.3 \%$ acid alcohol for 1-2 s. The sections were then rinsed in running distilled water and then in Scott's tap water, followed by distilled water again. The sections were then stained with eosin for $\sim 5 \mathrm{~s}$.

Published by Bioscientifica Ltd. 


\section{Immunohistochemistry}

IHC was carried out on $5 \mu \mathrm{m}$ paraffin-embedded sections. The sections were deparaffinized in xylene and antigen retrieval was carried out in $0.01 \mathrm{M}$ citric acid buffer $(\mathrm{pH} 6)$ using a microwave oven (three bursts of 5 min duration). The sections were then rinsed in PBS (0.1 M, pH 7.4) incubated with $3 \%$ hydrogen peroxide for $20 \mathrm{~min}$ at room temperature to block endogenous peroxidase activity, and then incubated with 5\% normal goat serum in $0.1 \mathrm{M}$ PBS containing 3\% BSA for $45 \mathrm{~min}$ at room temperature to block non-specific binding. The sections were then incubated for $12 \mathrm{~h}$ at $4{ }^{\circ} \mathrm{C}$ with primary antibody in 0.1 M PBS (Table 1). The sections used for STAR negative controls were incubated overnight with antibody pre-incubated with antigen (STAR blocking peptide (sc-23524P)) in place of the primary antibody. The sections were then washed three times in PBS and incubated for $1 \mathrm{~h}$ at room temperature with the appropriate IgG secondary antibody (biotinylated anti-rabbit (P450c17, Cytb5), antigoat (3ßHSD, StAR), or anti-mouse (tyrosine hydroxylase $(\mathrm{TOH})$ ) at 1:250 dilution (all Vector Laboratories, Burlingame, CA, USA). Antibody binding was visualized using streptavidin HRP (1:200; Amersham Biosciences), with metal-enhanced diaminobenzidine (Pierce Biotechnology, Inc., Rockford, IL, USA) as the chromogen.

\section{Immunonblotting}

Immunoblotting was used to verify the specificity of the STAR protein in the adult spiny mouse. Total protein from male and female adult spiny mice (170 days old) was extracted from snap-frozen adrenals and concentration determined using a Pierce BCA protein assay kit (Thermo Fisher Scientific, Scoresby, VIC, Australia). Protein (35 $\mu \mathrm{g})$ was subjected to a reducing SDS-PAGE and transferred onto a PVDF membrane (Immobilon-P, Millipore, Billerica, MA, USA). The membrane was blocked with $5 \%$ skim milk in PBS/0.5\% Tween-20 (PBS/T) before incubation with primary antibody overnight at $4{ }^{\circ} \mathrm{C}$ (polyclonal goat anti-STAR; 1:200, Santa Cruz Biotechnology). The membrane was then incubated with secondary antibody (1:1000 rabbit anti-goat HRP, Serotec, Oxford, UK) at room temperature for $1 \mathrm{~h}$ and the immune-labeled protein visualized using an Immobilon Western Chemiluminescent HRP substrate (Millipore).

\section{Quantification of histology and IHC}

Sections were viewed using an Olympus microscope and images were captured using a Nikon digital camera and DP2 BSW computer program. For each adrenal gland, the results of three fields of view per section, per adrenal zone (zona reticularis (ZR), zona fasciculata (ZF), and zona glomerulosa $(Z G)$ ), for six sections per adrenal gland, were averaged for each animal and then the results averaged for all animals in each group. Densitometric analysis using ImageJ (National Institutes of Health, Bethesda, MA, USA) was used to calculate the percentage area of the field of view occupied by positive staining. The color images were converted to gray scale, and the positive signal was expressed as the relative number (\%) of pixels above background (threshold). Data from DEX/saline-treated animals are expressed as a percent change from untreated control animals.

\section{Data analysis and statistical analysis}

All data are expressed as mean \pm s.E.M. with only one male and one female offspring from any 11 sampled at $170 \pm 20$ days of age used for the analysis. Statistical significance was determined using statistical analysis software (Prism, GraphPad Software, Inc., La Jolla, CA, USA). Adrenal weight-to-body weight ratio differences between groups were assessed using one-way independent measures ANOVA, with the Tukey's test applied post hoc. Treatmentdependent changes in the plasma concentrations of DHEA, testosterone, and cortisol were analyzed using the two-way

Table 1 Primary antibodies used for immunohistochemical analysis

\begin{tabular}{|c|c|c|c|}
\hline Primary antibody & Antigen & Source & Dilution \\
\hline STAR protein & $\begin{array}{l}\text { Polyclonal goat anti-human StAR (K-20) } \\
\text { (sc-23524) }\end{array}$ & Santa Cruz Biotechnology & $1: 100$ \\
\hline P450C17 & Polyclonal rabbit anti-bovine P450c17 & Alan Conley (Univ. Davis, CA, USA) & $1: 1000$ \\
\hline Cytochrome b5 & Polyclonal rabbit anti-human cytochrome b5 & Alan Conley & $1: 1000$ \\
\hline $\begin{array}{l}\text { 3ß-Hydroxysteroid } \\
\text { dehydrogenase }\end{array}$ & $\begin{array}{l}\text { Polyclonal goat anti-human } \\
3 \beta \text {-hydroxysteroid dehydrogenase }\end{array}$ & Santa Cruz Biotechnology & $1: 100$ \\
\hline Tyrosine hydroxylase & Monoclonal mouse anti-rat tyrosine hydroxylase & Boehringer (Mannheim, Germany) & $1: 1000$ \\
\hline
\end{tabular}

http://joe.endocrinology-journals.org DOI: $10.1530 /$ JOE-13-0514 (c) 2014 Society for Endocrinology Printed in Great Britain
Published by Bioscientifica Ltd. 
independent measures ANOVA with the Bonferroni's post hoc test. Treatment-dependent differences between the DEX and saline groups in percentage of positive enzyme expression relative to controls (untreated), as determined by IHC, were analyzed using the two-way independent measures ANOVA with the Bonferroni's post hoc test. Statistical significance was accorded when $P<0.05$. Where there were no significant differences between males and females (steroidogenic enzyme expression at each of 20 and 30 days of gestation; enzyme expression between the control (untreated) and saline-treated animals for both males and females at $170 \pm 20$ days of age; and DEX vs saline adrenal structure as shown by H\&E and TOH IHC), only representative images of male adrenals have been shown.

\section{Results}

Steroidogenic enzyme expression in the spiny mouse adrenal gland at $\mathbf{2 0}$ and $\mathbf{3 0}$ days of gestation, and at $170 \pm 20$ days of age in control (untreated) animals

Fetal adrenal development There was a large increase in the size of the fetal adrenal gland between 20 days of gestation (Fig. 1A, B, C and D) and 30 days of gestation (Fig. 1E, F, G and H), accompanied by increased expression of STAR, 3BHSD, P450C17, and CYTB5 over this time (0.5-0.75 gestation). At 20 days of gestation, there was cytoplasmic staining of both STAR and CYTB5 (Fig. 1A and C) throughout the whole adrenal gland, but not P450C17 or 33HSD protein. By 30 days of gestation,

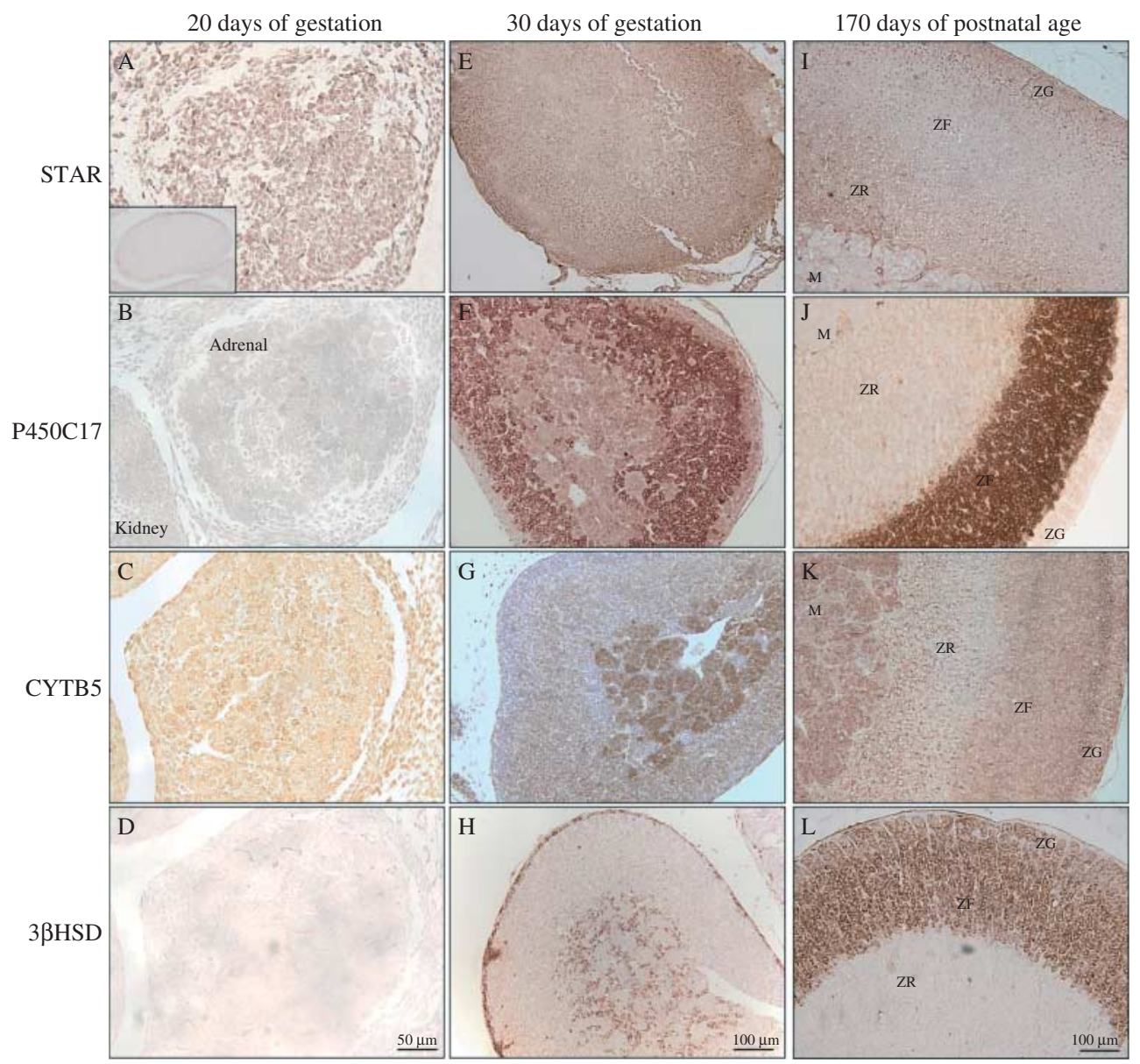

\section{Figure 1}

Immunohistochemical localization of STAR (A, E and I), P450C17 (B, F and J), CYTB5 ( $C, G$ and $K$ ), and 3BHSD (D, H and $L$ ) in the developing adrenal gland of male spiny mouse at 20 days of gestation $(A, B, C$ and $D)$ and 30 days of gestation $(E, F, G$ and $H)$, and at 170 days of postnatal $(P)$ age $(I, J, K$ and $L)$.
Insert in (A) shows negative control (antibody pre-incubated with antigen) for the STAR protein at 20 days of gestation. Scale bar $=50 \mu \mathrm{m}$ in (A, B, C and $D)$ and $100 \mu \mathrm{m}$ in (E, F, G, H, I, J, K and L). http://joe.endocrinology-journals.org DOI: $10.1530 / J O E-13-0514$
(C) 2014 Society for Endocrinology Printed in Great Britain 
STAR protein was predominantly localized in the middle of the presumptive cortex, while CYTB5 immunoreactivity was still present in both the medulla and cortex, although with clearly decreased expression in the outer region of the cortex, the presumptive ZG (Fig. 1E and G). At 20 days of gestation, the expression of P450C17 in the fetal adrenal gland was very low and no expression of $3 \beta \mathrm{HSD}$ could be detected (Fig. 1B and D). However, by 30 days of gestation P450C17 was widely distributed, with strong expression in cells surrounding the presumptive medulla and occupying most of the cortex (Fig. 1E). 3 $\beta$ HSD immunoreactivity was present in cells surrounding the medulla and also in the ZG (Fig. 1H).

Adult adrenal gland At $170 \pm 20$ days of age, STAR protein was expressed throughout the adrenal cortex, with no greater or lesser expression evident for the ZG, ZF, and ZR (Fig. 1I). P450C17 immunoreactivity was observed in the $\mathrm{ZR}$ and $\mathrm{ZF}$ only, with the strongest expression in the ZF (Fig. 1J). CYTB5 expression was present throughout the adrenal cortex and the medulla in the adult gland (Fig. 1K). 33HSD expression was found predominantly in the ZF and ZG in the adrenal gland of adult offspring (Fig. 1L).

\section{Effect of maternal DEX treatment on body and adrenal weights and adrenal morphology at $170 \pm 20$ days of age}

DEX treatment at 20 days of gestation did not significantly affect the body weight of $170 \pm 20$-day-old male or female offspring, whereas treatment at 30 days of gestation resulted in a significant increase in body weight of male spiny mice (Table 2). The adrenal glands of male and female offspring were not significantly affected by the DEX treatment at either 20 or 30 days of gestation (Table 2). Hematoxylin and eosin staining of the adrenal cortex and $\mathrm{TOH}$ immunohistochemical analysis of the adrenal medulla showed no obvious gross structural differences between the male and female adult offspring of saline and DEX-treated mothers, irrespective of whether the DEX had been administered at 20 days of gestation (Fig. 2A, B, C and D) or 30 days of gestation (Fig. 2E, F, G and H).

\section{Effect of DEX treatment during pregnancy on steroidogenic enzyme expression at $170 \pm 20$ days of age}

STAR After maternal DEX at 20 days of gestation, STAR expression was significantly decreased in the ZR of male (percentage of positive staining relative to control: DEX $-13.73 \pm 4.67 \%$ vs saline $+5.59 \pm 4.18 \%$; $P<0.05)$, but not in female adult offspring (DEX $-2.02 \pm 4.94 \%$ vs saline $+3.77 \pm 3.78 \%$ ), whereas it was increased in the ZG of males $(\mathrm{DEX},+33.09 \pm 9.26 \%$ vs saline $+3.82 \pm 0.15 \%$; $P<0.05)$ and decreased in ZG of females (DEX $-37.84 \pm$ 9.14\% vs saline $+4.25 \pm 0.23 \% ; P<0.001$; Fig. $3 \mathrm{D}$ and $\mathrm{E})$. In contrast, DEX treatment at 30 days of gestation had no significant effect on STAR expression in any cortical zone of the adrenal gland at $170 \pm 20$ days of age (Fig. 3J).

P450C17 DEX treatment at 20 days of gestation had the effect of significantly decreasing P450C17 immunoreactivity in the $\mathrm{ZR}$ of male offspring only (percentage of positive staining relative to control: DEX $-61.12 \pm 6.56 \%$ vs saline $+1.69 \pm 2.96 \% ; P<0.001 ;$ Fig. $4 \mathrm{E}$ ), with no effects on expression in the ZF of either sex. DEX treatment at

Table 2 Body weight (BW), combined adrenal weight (absolute (mg)) and adrenal weight expressed relative to BW in $170 \pm 20$-dayold-offspring of saline and dexamethasone (DEX)-treated mothers at 20 and 30 days of gestation. Values are expressed as mean \pm S.E.M.

\begin{tabular}{|c|c|c|c|c|c|c|c|c|}
\hline & \multicolumn{4}{|c|}{20 Days of treatment } & \multicolumn{4}{|c|}{30 Days of treatment } \\
\hline & $\begin{array}{l}\text { Control } \\
(n=6)\end{array}$ & $\begin{array}{l}\text { Saline } \\
(n=6)\end{array}$ & $\begin{array}{l}\text { DEX } \\
(n=6)\end{array}$ & $\begin{array}{l}P \text { value } \\
\text { (saline vs } \\
\text { DEX) }\end{array}$ & $\begin{array}{l}\text { Control } \\
(n=7)\end{array}$ & $\begin{array}{l}\text { Saline } \\
(n=6)\end{array}$ & $\begin{array}{l}\text { DEX } \\
(n=6)\end{array}$ & $\begin{array}{l}P \text { value } \\
\text { (saline vs } \\
\text { DEX) }\end{array}$ \\
\hline \multicolumn{9}{|l|}{ Male offspring } \\
\hline Body weight (g) & $39.9 \pm 0.3$ & $32.5 \pm 1.0$ & $33.8 \pm 0.7$ & NS & $36.5 \pm 1.3$ & $38.9 \pm 0.5$ & $42.7 \pm 0.7$ & $<0.01$ \\
\hline Adrenal weight (mg) & NA & $\mathrm{NA}^{\mathrm{a}}$ & NA & NA & $20.1 \pm 0.02$ & $23 \pm 1.0$ & $47+17.0$ & NS \\
\hline Adrenal weight (mg/g BW) & NA & NA & NA & NA & $0.5 \pm 0.2$ & $0.6 \pm 0.03$ & $1.2 \pm 0.5$ & NS \\
\hline \multicolumn{9}{|l|}{ Female offspring } \\
\hline Body weight (g) & $29.9 \pm 1.66$ & $30.4 \pm 1.1$ & $29.3 \pm 0.7$ & NS & $32.9 \pm 0.7$ & $35.3 \pm 0.939$ & $36.9 \pm 1.226$ & NS \\
\hline Adrenal weight (mg) & NA & NA & NA & NA & $22.5 \pm 0.01$ & $23 \pm 2.0$ & $33 \pm 18.0$ & NS \\
\hline Adrenal weight $(\mathrm{mg} / \mathrm{g} \mathrm{BW})$ & NA & NA & NA & NA & $0.68 \pm 0.01$ & $0.65 \pm 0.071$ & $0.873 \pm 0.453$ & NS \\
\hline
\end{tabular}

NS, not significant.

${ }^{a}$ Adrenal weights were not available (NA) at time of post mortem.

http://joe.endocrinology-journals.org DOI: $10.1530 / \mathrm{JOE}-13-0514$ (c) 2014 Society for Endocrinology Printed in Great Britain
Published by Bioscientifica Ltd 


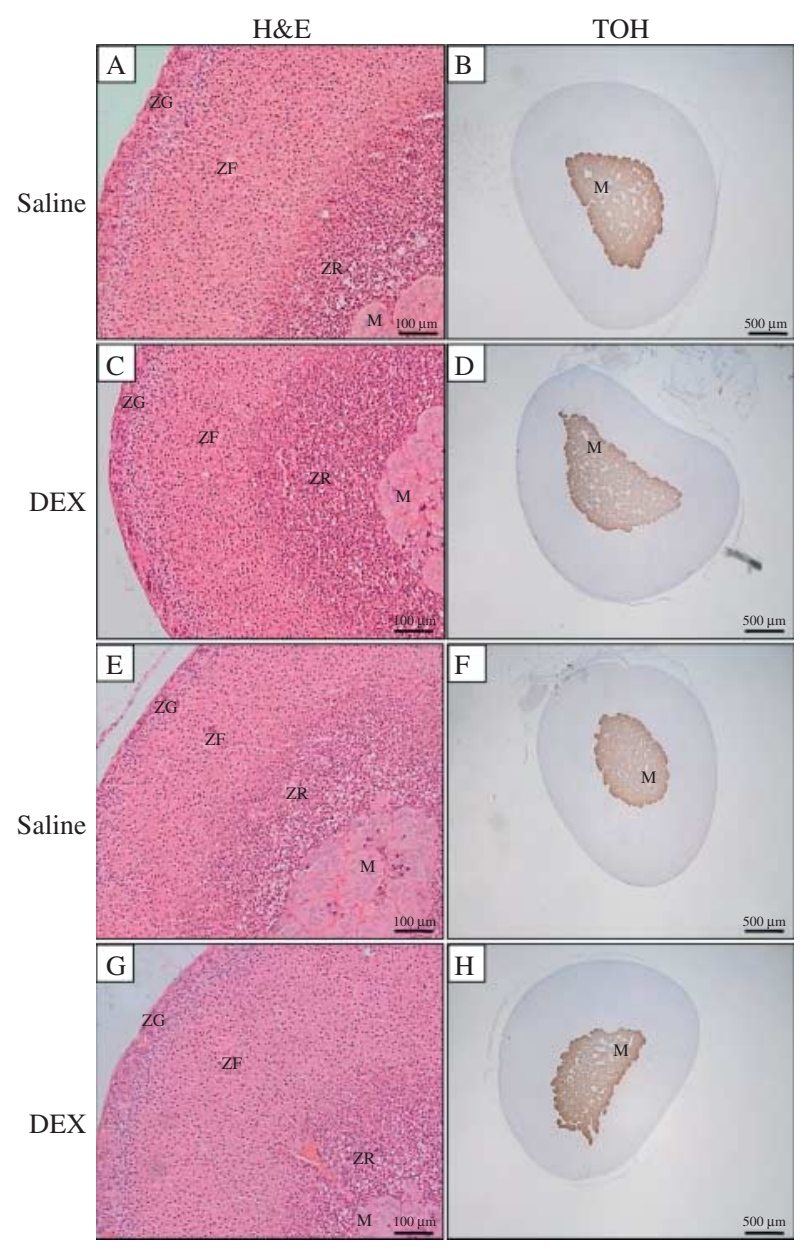

Figure 2

Hematoxylin and eosin staining ( $A, C, E$ and $G$ ) and tyrosine hydroxylase $(\mathrm{TOH})$ immunohistochemistry $(B, D, F$ and $H)$ in the adrenal gland of adult (170 days of postnatal age) offspring of saline ( $A, B, E$ and $F$ ) and DEX-treated dams (C, D, G and H). ( $A, B, C$ and $D$ ) Male adult offspring from dams treated with DEX or saline at 20 days of gestation. (E, F, G and $H$ ) Male adult offspring from dams treated at 30 days of gestation. Scale bars: $100 \mu \mathrm{m}$ in $\mathrm{A}, \mathrm{C}, \mathrm{E}$ and $\mathrm{G}$; and $500 \mu \mathrm{m}$ in $\mathrm{B}, \mathrm{D}, \mathrm{F}$ and $\mathrm{H}$.

30 days of gestation had no effect on P450C17 expression in the ZR or ZF of either male or female spiny mice at 170 \pm 20 days of age (Fig. 4J). As mentioned earlier, P450C17 was not present in the ZG of the adult adrenal gland.

Cytochrome b5 DEX treatment at either 20 or 30 days of gestation had the effect of reducing CYTB5 expression in the ZR and ZF of the adrenal cortex of male offspring, with no significant effect on expression in those zones of the female adrenal cortex, and no effect on the $Z G$ in either sex (Fig. 5A, B, C, D, E, F, G, H and I).

3ß-Hydroxysteroid dehydrogenase DEX treatment had no significant effect on $3 \beta \mathrm{HSD}$ expression throughout the adrenal gland of male and female spiny mice at $170 \pm 20$ days of age (Fig. 6A, B, C, D, E, F, G, H, I and J), although there was a trend $(0.05<P<0.1)$ for decreased expression of $3 \beta \mathrm{HSD}$ in the ZG of the female offspring after treatment at 20 days of gestation. 3 3 HSD expression was limited to the $\mathrm{ZF}$ and the $\mathrm{ZG}$ in all females regardless of treatment (Fig. 6G and I). Unexpectedly however, the male offspring of mothers exposed to prenatal DEX at 30 days of gestation showed increased immunoreactivity of $3 \beta \mathrm{HSD}$ in the $\mathrm{ZR}$ (Fig. $6 \mathrm{H}$ ), a result not found in the saline-treated control males (Fig. 6F) or untreated age-matched control males (see Fig. 1L).

\section{Plasma steroid levels in adult offspring exposed to maternal DEX or saline treatment during pregnancy}

The DEX treatment at 20 days of gestation resulted in significantly decreased plasma concentrations of DHEA in $170 \pm 20$-day-old male offspring (DEX 6.84 $\pm 1.24 \mathrm{ng} / \mathrm{ml}$ vs saline $13.06 \pm 0.27 \mathrm{ng} / \mathrm{ml} ; P<0.05)$, but not in female spiny mice at this age (Fig. 7A). In the males, there was a trend $(P=0.27)$ for plasma cortisol to be increased after the DEX treatment (Fig. 7B), and the plasma DHEA:cortisol ratio was significantly decreased, a change not observed in female offspring (Fig. 7C). After DEX treatment at 20 days of gestation, plasma testosterone concentrations were significantly higher in adult male offspring (DEX $266.03 \pm 50.75 \mathrm{pg} / \mathrm{ml}$ vs saline $83.47 \pm$ $32.3 \mathrm{pg} / \mathrm{ml} ; P<0.05$ ), an effect not observed in females at this age (Fig. 7D).

DEX treatment at 30 days of gestation had no effect on the absolute and relative concentrations of DHEA and cortisol in either sex (Fig. 7E, F and G), although significant differences in the plasma concentration of cortisol between male $(351.03 \pm 59.69 \mathrm{ng} / \mathrm{ml})$ and female $(724.99 \pm 94.24 \mathrm{ng} / \mathrm{ml} ; P<0.01)$ spiny mice were noted (Fig. 7F). After treatment at 30 days of gestation there were no significant differences in testosterone concentrations between the DEX - vs saline - treated adult offspring, but as expected, adult males showed significantly higher circulating testosterone concentrations compared to females (Fig. 7H).

\section{Discussion}

The effects of the DEX treatment at 20 or 30 days of gestation are summarized in Table 3 . The principal finding of this study is that a pulse of glucocorticoid delivered at 0.5 , but not at 0.75 , of pregnancy in the spiny mouse significantly alters the developmental trajectory of the

Published by Bioscientifica Ltd. 


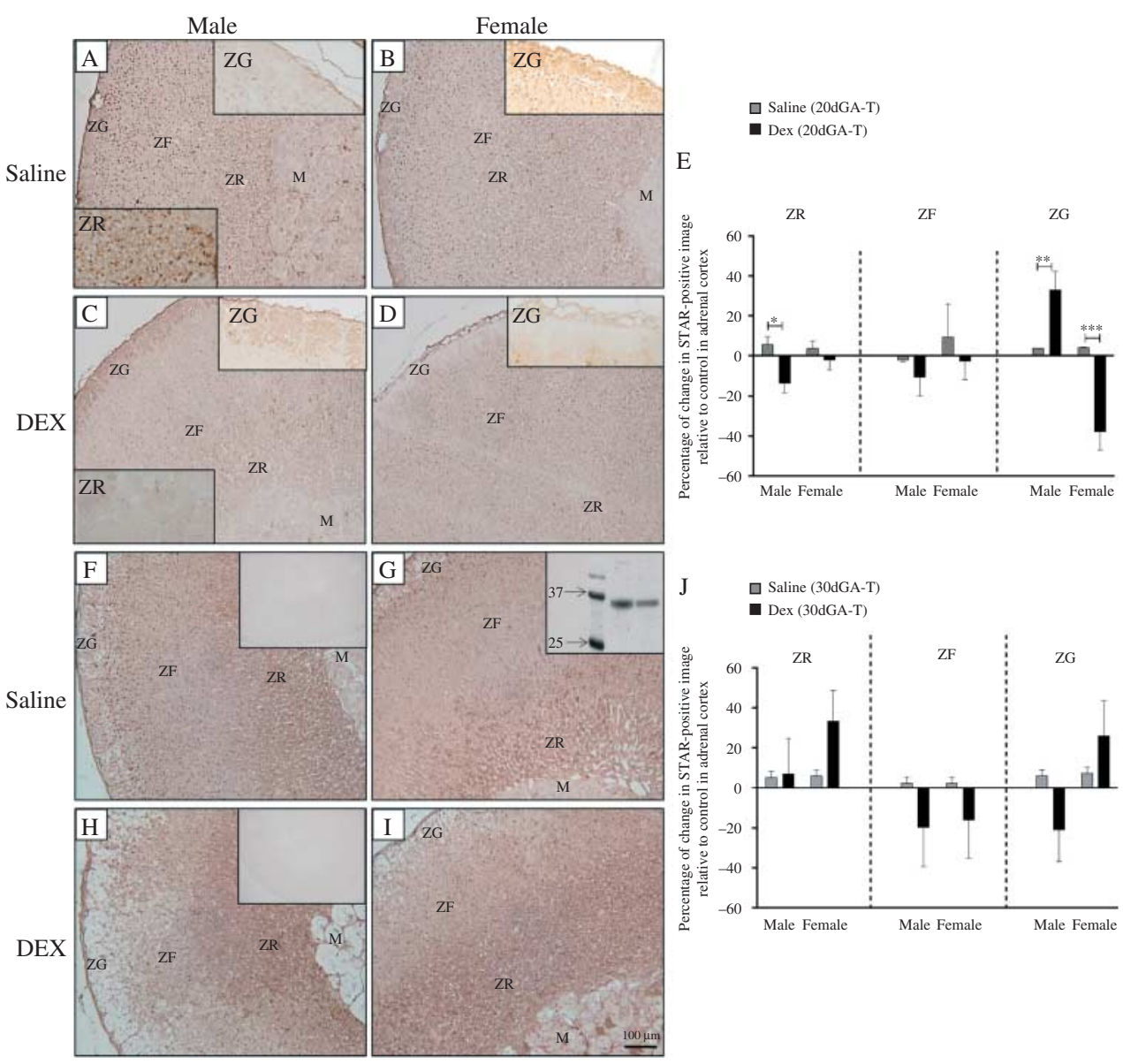

Figure 3

Immunohistochemical localization (A, B, C, D, F, G, H and I) and percentage positive image relative to control ( $E$ and J) of STAR protein in the zona reticularis (ZR), zona fasciculata (ZF), and zona glomerulosa (ZG) in male and female adult offspring from dams treated with saline or dexamethasone (DEX) at 20 days of gestation (A, B, C, D and E) or 30 days of gestation $(F, G, H, I$ and $J)$. Inserts in (A, $B, C$ and $D)$ show high magnification of STAR expression in the $Z R(A$ and $C$ ) and $Z G(A, B, C$ and $D)$ in the adult offspring

fetal male spiny mouse adrenal glands, resulting in decreased secretion of DHEA at $170 \pm 20$ days after birth. At 20 days (0.5) gestation, the protein STAR and the accessory hemoprotein CYTB5 were expressed in the adrenal gland, but the enzymes P450c17 and 33HSD were not expressed at this stage. However, by 30 days (0.75) of gestation, all four enzymes were expressed, and the adrenal cortex had clearly differentiated into zones that prefigured the definitive development of the ZR, ZF, and ZG.

Glucocorticoid exposure at 0.5 gestation resulted in changes in the expression of the key proteins of DHEA synthesis in the adult adrenal cortex, and many of these effects were greater in males. DEX given at 0.5 gestation resulted in a decrease in STAR, P450C17, and CYTB5 of 20 days of gestation DEX- or saline-treated mothers. Inserts in ( $F$ and $H$ ) show negative control (no primary antibody) adrenal glands of male offspring of mothers treated with DEX or saline at 30 days of gestation. Insert in (G) shows immunoblot verification of enzyme expression and antibody specificity for STAR protein in male (lane 1) and female (lane 2) spiny mouse adult adrenal glands at 170 days of age. $* P \leq 0.05, * * P \leq 0.01$, and $* * * P \leq 0.001$ DEX vs saline; scale bar $=100 \mu \mathrm{m}$.

expression in the ZR of male adult offspring and, with exception of CYTB5, these changes were not observed in the ZF. As STAR is required in the rate-limiting step involved in all steroidogenic reactions (Clark et al. 1994, Miller \& Auchus 2011), and CYTB5 allosterically modulates the 17-20lyase activity of P450C17 (Katagiri et al. 1995, Lee-Robichaud et al. 1995), it is likely that the decreased expression of these enzymes in the ZR may be responsible for the decreased levels of circulating DHEA that were present in the adult male offspring of these pregnancies.

In the ZF, expression of STAR, P450C17, and 3BHSD was not significantly altered in offspring exposed to the mid-gestation maternal DEX treatment, and accordingly,

Published by Bioscientifica Ltd. 

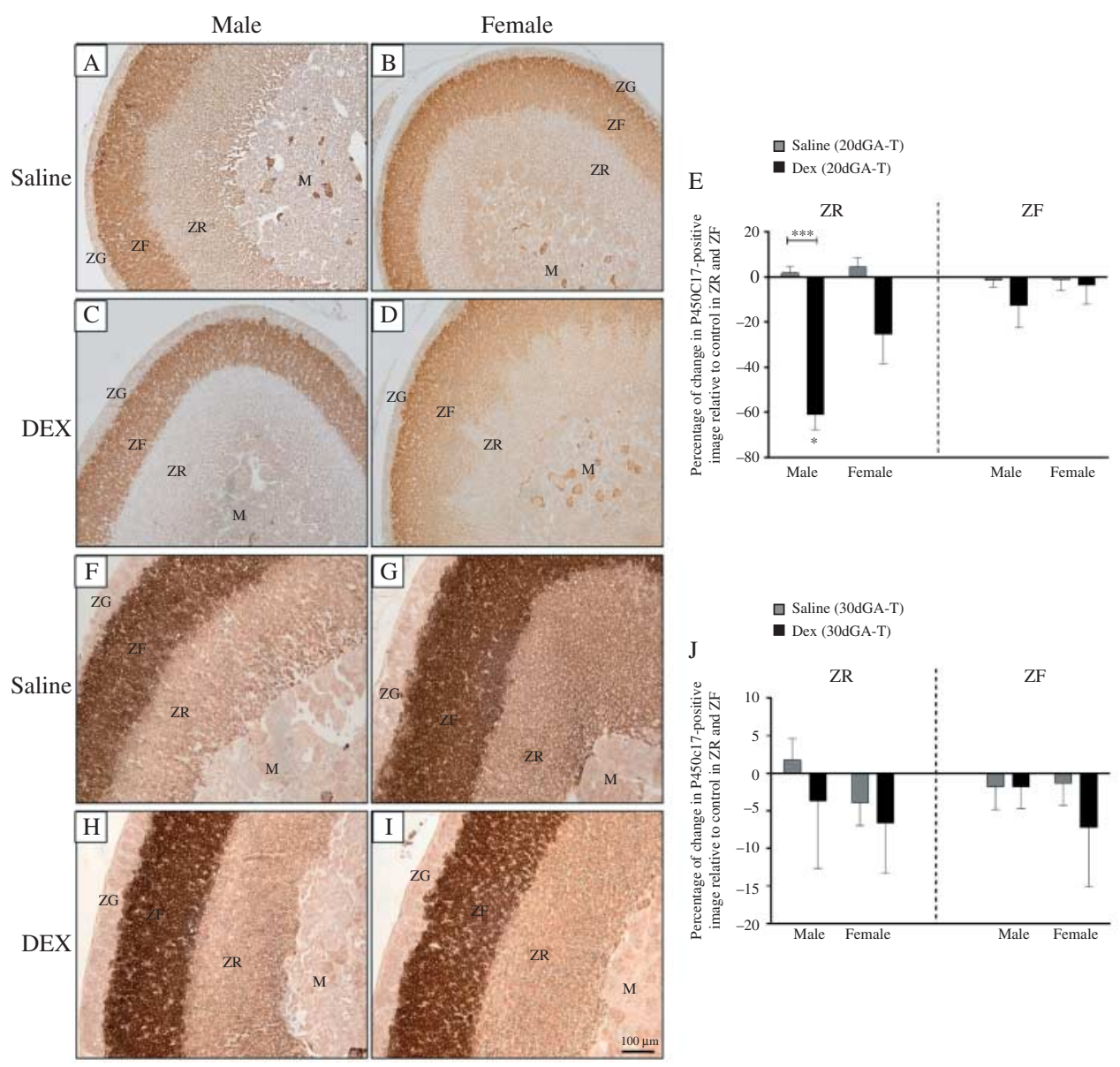

\section{Figure 4}

Immunohistochemical localization (A, B, C, D, F, G, H and I) and percentage positive image relative to control ( $E$ and $J$ ) of $P 450 C 17$ in the $Z R$ and $Z F$ in male and female adult offspring of dams treated with saline or dexamethasone (DEX) at 20 days of gestation ( $A, B, C, D$ and $E$ ) or 30 days of gestation ( $F, G, H, I$ and J). (E) A significant decrease in $P 450 C 17$ expression (expressed as percentage of positive staining/image area - see 'Materials

cortisol levels did not differ significantly between the DEX and saline treatment groups. It is possible that the decrease in CYTB5 in the ZF may act to direct the synthesis of 17-hydroxy-pregnenolone to 17-hydroxyprogesterone rather than DHEA. Together, these findings indicate that maternal stress can program the development of the fetal adrenal gland so that there is diminished adrenal production of DHEA and preferential synthesis and secretion of cortisol. Such change of steroidogenesis also occurs in human patients with acute physiologic stress, such as burns (Lephart et al. 1987), serious illnesses (Carlström et al. 1990, Oberbeck \& Kobbe 2010), and schizophrenia (Ritsner et al. 2004). Interestingly, testosterone and androstenedione concentrations have also been observed to decline in men and methods' section) in the ZR of male adult offspring of mothers exposed to $D E X$ at 20 days of gestation. ${ }^{* *} P \leq 0.001 \mathrm{DEX}$ vs saline; scale bar $=$ $100 \mu \mathrm{m}$. DEX, dexamethasone; ZR, zona reticularis; ZF, zona fasciculata; ZG, zona glomerulosa; $M$, medulla; 20dGA-T, adult offspring of mothers treated at 20 days of gestation; 30dGA-T, adult offspring of mothers treated at 30 days of gestation.

exposed to burn trauma, while cortisol concentrations were elevated (Dolecek 1989).

After DEX treatment at 20 days of gestation in the pregnant spiny mouse, there was increased expression of STAR protein in the adrenal gland of male offspring, but decreased expression in female offspring. There was also a decrease in 3 $3 \mathrm{HSD}$ expression in the $\mathrm{ZG}$ of female offspring, suggesting altered capacity of female offspring to produce aldosterone from this zone. Female offspring also showed a trend for this mid-gestation DEX treatment to decrease plasma DHEA and cortisol, suggesting there may be a general underactivity of the HPA axis in female offspring exposed to prenatal DEX treatment.

These effects of DEX treatment during pregnancy on the adult spiny mouse adrenal gland are consistent with

Published by Bioscientifica Ltd 


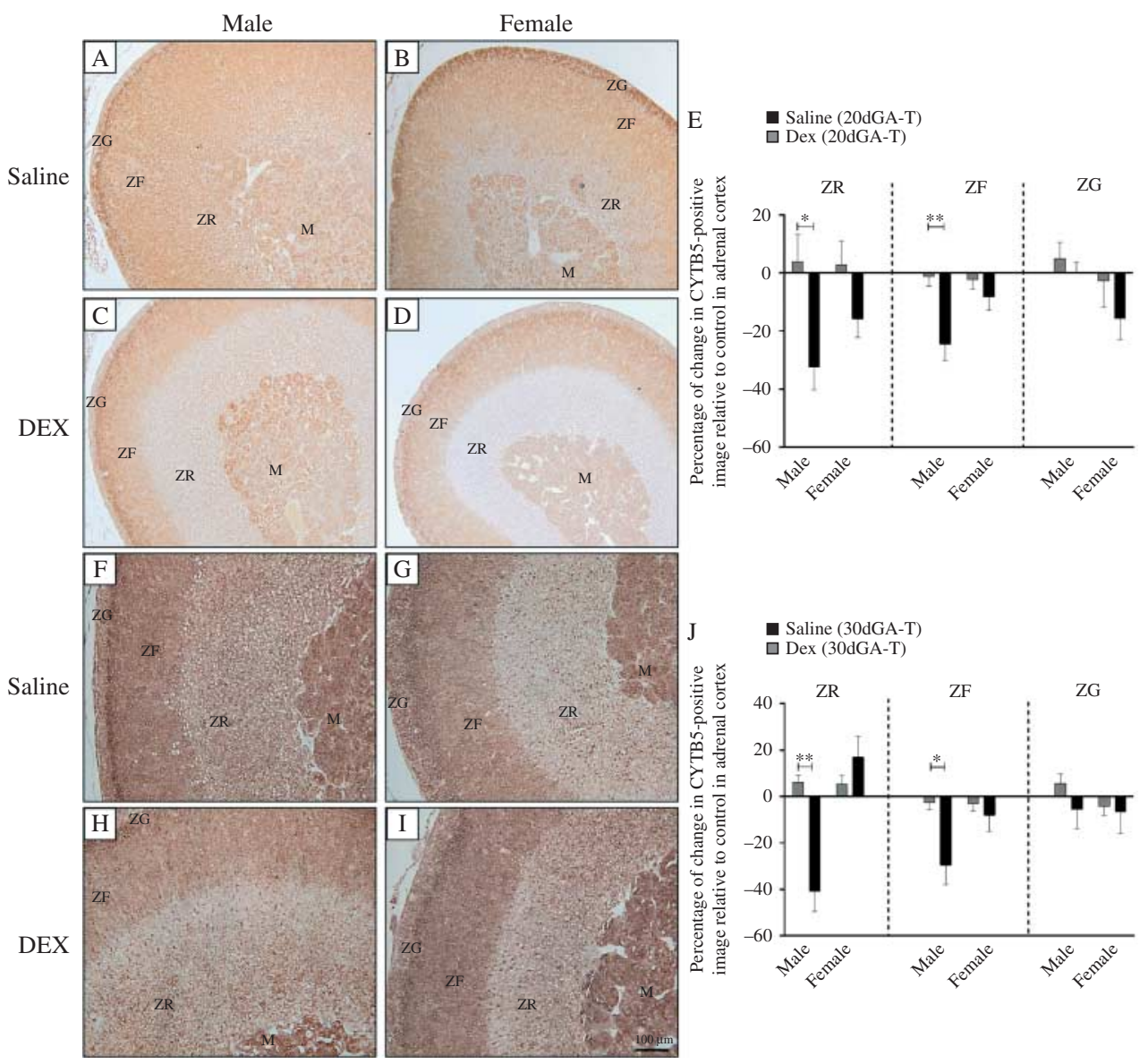

Figure 5

Immunohistochemical localization (A, B, C, D, F, G, H and I) and percentage positive image relative to control ( $E$ and J) of cytochrome b5 (CYTB5) in the $\mathrm{ZR}, \mathrm{ZF}$, and $\mathrm{ZG}$ in male and female adult offspring of dams treated with saline or DEX at 20 days of gestation (A, B, C, D and E) or 30 days of gestation $(F, G, H, I$ and $J) . * P \leq 0.05$ and $* * P \leq 0.01$ DEX vs saline.

other studies, in which stress induced by undernutrition in rats, from day 10 of gestation until delivery, resulted in a decrease in several steroidogenic enzyme mRNAs in the adult adrenal gland (Khorram et al. 2008, 2011). In this model of nutritional maternal stress, adrenal profiles of steroidogenic enzymes in adult offspring were also markedly altered in a sex-specific manner, with significant decreases evident in P450c17 (Cyp17a1) mRNA expression and increased P450scc (Cyp11a1) and aldosterone synthase expression in the male offspring (Khorram et al. 2011). These changes confirm that maternal stress in pregnancy provokes gender-specific effects in the development of the adrenal cortex, and the similarity to the DEX-induced changes observed in the current study further implicates maternal cortisol as the factor that 'programs' the development of the adrenal gland. Further research is
Scale bar $=100 \mu \mathrm{m}$. DEX, dexamethasone; $Z R$, zona reticularis; $Z F$, zona fasciculata; ZG, zona glomerulosa; $\mathrm{M}$, medulla; 20dGA-T, adult offspring of mothers treated at 20 days of gestation; 30dGA-T, adult offspring of mothers treated at 30 days of gestation.

necessary to establish when major programing effects on adrenal enzyme expression occur (i.e. during fetal life, after birth, or in early postnatal or adolescent periods), and the possibility that these changes may, at least in part, be mediated at different levels of the HPA axis.

In contrast to the effects of DEX administration at 20 days of gestation, and despite significant increase in the relative and absolute weight of the adrenal gland in males, there were no significant changes in STAR or P450C17 expression in the ZR or ZF, or of 3BHSD in the ZF following the DEX treatment at 30 days of gestation. Accordingly, the circulating levels of both DHEA and cortisol in these adult offspring did not significantly differ between the DEX and saline treatment groups. However, 3ßHSD expression in the ZF was significantly higher in males compared with females, a fundamental difference between

Published by Bioscientifica Ltd. 

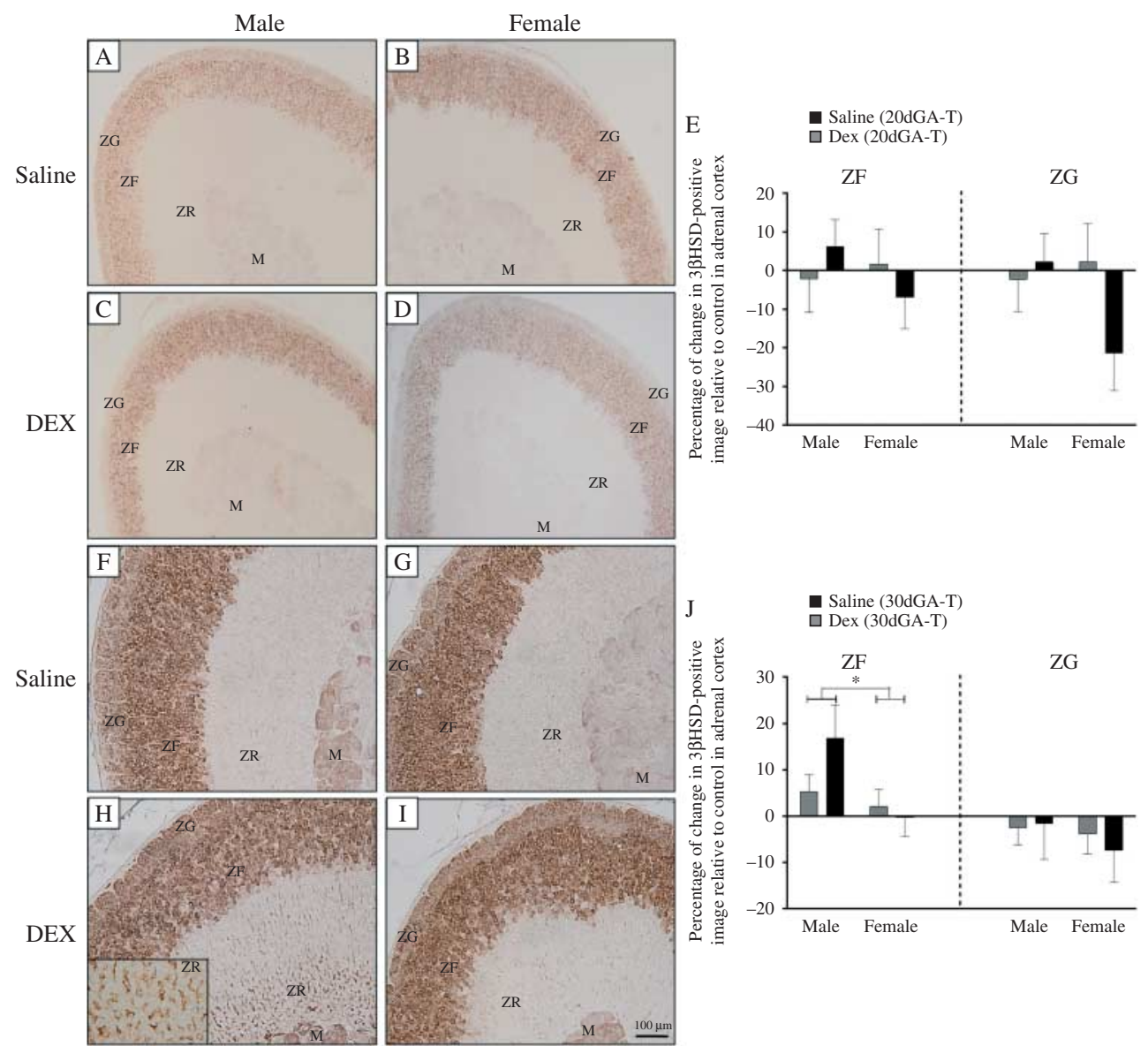

\section{Figure 6}

Immunohistochemical localization ( $A, B, C, D, F, G, H$ and I) and expression relative to control ( $E$ and $J$ ) of $3 \beta$-hydroxysteroid dehydrogenase (3BHSD) in the $Z F$ and $Z G$ in male and female adult offspring of saline and DEX treated mothers at 20 days of gestation (A, B, C, D and E) and 30 days of gestation $(F, G, H, I$ and $J)$. Insert in $(H)$ shows high magnification of the $Z R$ in male

males and females (regardless of treatment). In addition, in the male offspring of mothers exposed to DEX at 30 days of gestation show an evidence of $3 \beta \mathrm{HSD}$ immunoreactivity in $\mathrm{ZR}$, a finding which was unexpected, given it did not occur in females, or in any offspring treated at 20 days of gestation with DEX, nor was it observed during normal development of the ZR in this species (Quinn et al. 2013), perhaps resulting in a decrease in DHEA biosynthesis. The observations show that increased glucocorticoids of maternal origin can profoundly affect the developmental trajectory of the adrenal gland. The effects depend on the time of gestation and the developmental status of the adrenal gland.

Humans infants younger than 5 years old exhibit a poorly developed adrenal ZR that also expresses $3 \beta \mathrm{HSD}$ (Rainey et al. 2002), but when the ZR expands at adult offspring of mothers treated with DEX at 30 days of gestation. $* P \leq 0.05$ DEX vs saline. Scale bar $=100 \mu \mathrm{m}$. DEX, dexamethasone; $Z R$, zona reticularis; ZF, zona fasciculata; $Z G$, zona glomerulosa; $M$, medulla; 20dGA$T$, adult offspring of mothers treated at 20 days of gestation; 30dGA-T, adult offspring of mothers treated at 30 days of gestation.

adrenarche the $3 \beta \mathrm{HSD}$ content falls restricting steroidogenesis to the $\Delta 5$-pathway throughout adolescence and adulthood, thus maintaining DHEA-S production (Auchus $\&$ Rainey 2003). While 3 3 HSD activity is essential for the synthesis of aldosterone and cortisol in the ZG and ZF, $3 \beta H S D$ expression in the ZR might have a negative impact on the biosynthesis of DHEA as it would lead to the synthesis of progesterone from pregnenolone, or of $17-\mathrm{OH}$ progesterone from 17-OH pregnenolone, rather than the formation of DHEA. Thus, $3 \beta \mathrm{HSD}$ expression in the ZR of the DEX-treated offspring in the spiny mouse, together with the decrease in CYTB5 in both the ZR and the ZF, may represent an enzymatic environment in which steroid flux is directed away from the $\Delta 5$-pathway toward cortisol synthesis, as well as converting DHEA itself to androstenedione. Indeed, there was a trend of increased

Published by Bioscientifica Ltd. 

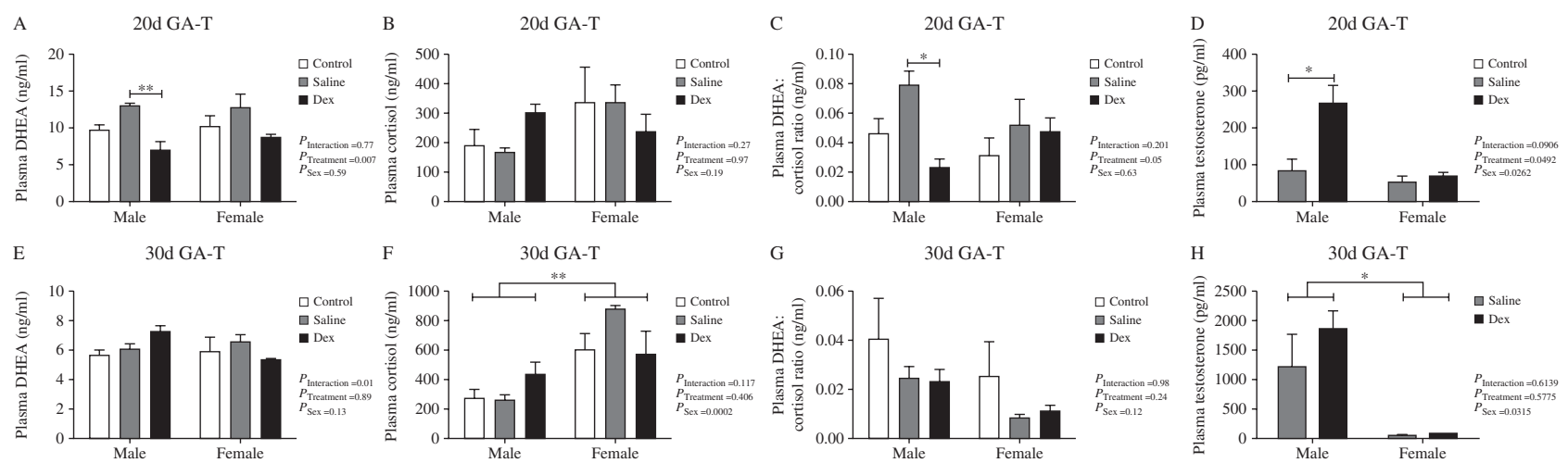

Figure 7

(A and E) Plasma DHEA concentrations; (B and F) plasma cortisol concentrations; ( $C$ and $G$ ) the DHEA:cortisol ratio; and ( $D$ and $H$ ) plasma testosterone concentrations in adult offspring of pregnant dams treated with either saline or DEX at $20(A, B, C$ and $D)$ or $30(E, F, G, H)$ days of

cortisol production in the male offspring exposed to DEX after treatment at 30 days of gestation, although the level of circulating cortisol was still below that of the females in both the DEX and saline treatment groups.

Other studies looking at the effects of glucocorticoid stress during late pregnancy have shown varying results. Waddell et al. (2010) found that DEX administered from day 13 to term in pregnant rats did not significantly alter the expression of Star mRNA in the adrenal gland of adult offspring, although plasma and urinary corticosterone and urinary aldosterone were elevated, indicative of enhanced adrenal responsiveness. Low-dose DEX given to rats during late pregnancy has been shown to reduce birth weight and result in hypertension, hyperglycemia, and hyperinsulinemia in adult offspring (Lindsay et al. 1996, Holness \& Sugden 2001, O'Regan et al. 2004). Studies in sheep, pigs, and guinea pigs have shown increased HPA axis activity and anxiety-like behaviors in adult offspring (Cadet et al. 1986, Lingas \& Matthews 2001, Sloboda et al. 2002, Jarvis et al. 2006), as well as increased adrenal the expression of Mc2r mRNA (Waddell et al. 2010), the gene encoding the ACTH receptor (Hirsch et al. 2011). These studies strongly suggest that maternal glucocorticoids mediate the effects of maternal stress on the development of the HPA axis in the fetus, and the results of this study in the spiny mouse show that the fetal adrenal gland is particularly vulnerable to high levels glucocorticoids even if they occur only transiently at mid-gestation. Previous studies have further shown that there is a reduction in glucocorticoid feedback sensitivity in late gestation in the guinea pig (Kapoor et al. 2006). Plasma cortisol concentrations in the fetal spiny mouse decrease from 30 days of gestation. ${ }^{*} P \leq 0.05$ and $* * P \leq 0.01$. DEX, dexamethasone; 20dGA-T, adult offspring of mothers treated at 20 days of gestation; 30dGA-T, adult offspring of mothers treated at 30 days of gestation.

gestation until the day of birth (Lamers et al. 1986, Quinn et al. 2013), suggesting that there is a developmental change in sensitivity to glucocorticoid feedback within the HPA axis after 30 days (0.75) of gestation.

This study has also shown that plasma testosterone concentrations were increased after the DEX treatment

Table 3 Summary of the effects of maternal administration of dexamethasone (DEX) at 20 or 30 days of gestation in male and female offspring at 170

\begin{tabular}{|c|c|c|c|c|}
\hline \multirow[b]{2}{*}{ DEX treatment at } & \multicolumn{2}{|c|}{ 20dGA } & \multicolumn{2}{|c|}{ 30dGA } \\
\hline & Male & Female & Male & Female \\
\hline Body weight & - & - & $\uparrow$ & - \\
\hline Adrenal weight & - & - & $\uparrow$ & - \\
\hline Plasma cortisol & - & - & - & - \\
\hline DHEA & $\downarrow$ & - & - & - \\
\hline DHEA:cortisol & $\downarrow$ & - & - & - \\
\hline $\begin{array}{l}\text { Testosterone } \\
\text { STAR }\end{array}$ & $\uparrow$ & - & - & - \\
\hline ZR & $\downarrow$ & - & - & - \\
\hline ZF & - & - & - & - \\
\hline ZG & $\uparrow$ & $\downarrow$ & - & - \\
\hline P450c17 & & & & \\
\hline ZR & $\downarrow$ & - & - & - \\
\hline ZF & - & - & - & - \\
\hline ZG & - & - & - & - \\
\hline Cytb5 & & & & \\
\hline ZR & - & - & - & - \\
\hline ZF & - & - & - & - \\
\hline ZG & - & - & - & - \\
\hline $3 \beta \mathrm{HSD}$ & & & & \\
\hline ZR & - & - & $\uparrow$ & - \\
\hline ZF & - & - & - & - \\
\hline ZG & - & - & - & - \\
\hline
\end{tabular}

Arrows, significant changes; -, no effect; GA, gestational age; P450c17,

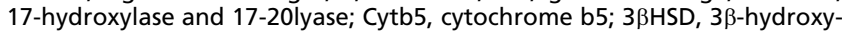
steroid dehydrogenase; $Z \mathrm{R}$, zona reticularis; $\mathrm{ZF}$, zona fasciculata; ZG, zona glomerulosa. 
at 20 days of gestation. This was an unexpected finding, considering that testosterone is an important downstream metabolite of DHEA (Labrie et al. 2001), and that plasma DHEA was significantly lower in these DEX-treated offspring, a change likely to follow from the decreased expression of $\mathrm{P} 450 \mathrm{C} 17$ in the adrenal gland. It is therefore likely that the high concentrations of testosterone in males are almost entirely testicular in origin, and so the possible effects of fetal DEX exposure on testicular function and the HPG axis are worthy of further investigation. The large difference in the plasma testosterone levels between the two groups treated with saline (tenfold difference 20 vs 30 days of gestation) suggests a greater effect of surgery at day 20 of gestation, possibly reflecting a shift in the maternal stress response or the expression and ratio of $11 \beta \mathrm{HSD} 1$ and 2 in the placenta between these two stages. Plasma from the offspring of the 'control' group was not available for analysis (due to limited volumes), but the male offspring of mothers treated with both DEX and saline at 30 days of gestation showed testosterone within the same range as 140-180 days old males observed in the spiny mouse colony used in our study (H Dickinson, J Mamrot, S Douglas, M Weybury, L Wiadrowski, D W Walker \& P TempleSmith, 2013, unpublished observations). It therefore appears that surgery had a major re-programing effect on the male HPG axis, and further studies could determine if testicular development and the onset of puberty are also altered in these offspring. This is possible because a previous study has shown that increased fetal glucocorticoid exposure delays onset of puberty in postnatal rats (Smith \& Waddell 2000).

It is certainly possible that stress caused by handling, surgery, and blood sampling may have influenced the circulating hormone concentrations reported in the current study. Previous studies in a variety of species have noted that even relatively short periods of handling stress can rapidly increase corticosterone concentrations in avian species, rodents, and reptiles (Harvey et al. 1980, Moore et al. 1991, Ryabinin et al. 1999), and although plasma levels of other hormones may change more slowly in response to stress, there is evidence in a variety of species that testosterone concentrations can decrease significantly within $15 \mathrm{~min}$ to an hour after handling stress (Wilson et al. 1979), and more extreme forms of stress such as social conflict (Huhman et al. 1991), electric foot shock, or immersion in cold water (Retana-Márquez et al. 2003). Importantly, surgery has also been shown to lower testosterone levels in males (Matsumoto et al. 1970), an effect that may, at least in part, be responsible for the tenfold decrease in testosterone concentrations observed in the current study between offspring of mothers treated with saline at 20 and 30 days of gestation.

Other studies of acute maternal stress at midpregnancy have found similar outcomes in adult offspring. For example, in pregnant guinea pigs maternal stress induced by treatment with a strobe light for $2 \mathrm{~h}$ /day over 3 days resulted in increased basal cortisol levels and significantly decreased plasma testosterone concentrations in male offspring (Kapoor et al. 2006). In addition, acute restraint stress has also been shown to increase adult plasma corticosterone, and reduce plasma dihydrotestosterone and $3 \alpha$-androstanediol, but not the aromatized metabolite estradiol in rats (Walf \& Frye 2012). Other studies in adult rats and mice (Pomerantz \& Pitelka 1998, Kostic et al. 1999) have shown that acute and chronic immobilization stress can result in a decrease in serum androgen concentrations, mediated by increased nitric oxide (NO) signaling in the testes, which specifically inhibits P450c17 activity (Kostic et al. 1999). It has been suggested that NO inhibits the activity of cytochrome P450 complexes by binding to the heme iron (Quaroni et al. 1996) or to the sulfhydryl groups in these enzymes (Snyder et al. 1996). Although these experiments were carried out in the testes, it is possible that the inhibition of P450C17 by NO may occur in the adrenal gland or brain of the spiny mouse, warranting further investigation in this species. In the rat, immobilization stress has been shown to increase NO synthase enzyme activity in the anterior pituitary, adrenal cortex, and adrenal medulla in adult animals (Kishimoto et al. 1996), and prenatal stress has been shown to cause gender-dependent neuronal loss and oxidative stress in the brain (Zhu et al. 2004), perhaps related to the decrease in the production of endogenous and systemic DHEA by P450c17.

In humans there is evidence that low levels of circulating DHEA with normal levels of cortisol place the developing brain at risk for a range of neuropsychiatric disorders, including major depressive disorder, bi-polar disorder, and anxiety (Wolkowitz \& Reus 2000, Goodyer et al. 2001, Harris et al. 2001, Ritsner et al. 2004). Low DHEA:cortisol ratios are observed in schizophrenia patients, and is positively associated with severity of depression, state and trait anxiety, trait anger, angry temperament, and hostility in such patients (Ritsner et al. 2004). As DHEA itself has been found to have potent anti-glucocorticoid and antioxidant effects in the brain (Bastianetto et al. 1999), it is possible that low circulating levels of DHEA may leave the brain increasingly vulnerable to oxidative damage. Interestingly, significantly

Published by Bioscientifica Ltd. 
increased total nitrite levels and increased oxidant end-products by the reactions of NO with other free radicals have been observed in the plasma samples of human patients with schizophrenia (Black et al. 1999, Akyol et al. 2004).

In summary, this study demonstrates that the adrenal gland is an important target for glucocorticoid programing effects, and highlights the possibility that acute stress at a critical stage of adrenal development may determine steroidogenic enzyme expression and steroid synthesis and secretion in adult life. The outcome also depends on the sex of the fetus. The complex and developmentally sensitive interactions between cortisol, DHEA, and adrenal steroidogenic enzymes in the spiny mouse may provide an appropriate model for studying the effects of in utero exposure to glucocorticoids on the etiology of mental disorders with a presumed developmental origin.

\section{Declaration of interest}

The authors declare that there is no conflict of interest that could be perceived as prejudicing the impartiality of the research reported.

\section{Funding}

This work was supported by the NHMRC Australia \& Cerebral Palsy Alliance Australia, and the Victorian Government's Operational Infrastructure Support Program to Monash Institute of Medical Research. H Dickinson is an ARC Australian Post-Doctoral Research Fellow.

\section{Acknowledgements}

The authors wish to acknowledge funding support from NHMRC Australia \& Cerebral Palsy Alliance Australia, and the Victorian Government's Operational Infrastructure Support Program to Monash Institute of Medical Research. The authors thank Prof. Alan J Conley (School of Veterinary Medicine, University of California - Davis, California, USA) for his generous provision of antibodies used in this study.

\section{References}

Adams W, Kendell RE, Hare EH \& Munk-Jorgensen P 1993 Epidemiological evidence that maternal influenza contributes to the aetiology of schizophrenia. An analysis of Scottish, English, and Danish data. British Journal of Psychiatry 163 522-534. (doi:10.1192/bjp.163.4.522)

Aiken CE \& Ozanne SE 2013 Sex differences in developmental programming models. Reproduction 145 R1-R13. (doi:10.1530/REP-11-0489)

Akyol O, Zoroglu SS, Armutcu F, Sahin S \& Gurel A 2004 Nitric oxide as a physiopathological factor in neuropsychiatric disorders. In Vivo 18 377-390.

Anisman H \& Merali Z 2003 Cytokines, stress and depressive illness: brain-immune interactions. Annals of Medicine 35 2-11. (doi:10.1080/ 07853890310004075)

Auchus RJ \& Rainey WE 2003 Adrenarche-physiology, biochemistry and human disease. Clinical Endocrinology 60 288-296. (doi:10.1046/ j.1365-2265.2003.01858.x)
Barker DJP 2004 The developmental origins of adult disease. Journal of the American College of Nutrition 23 588S-595S. (doi:10.1080/07315724. 2004.10719428)

Barrett-Connor E, Khaw KT \& Yen SS 1986 A prospective study of dehydroepiandrosterone sulfate, mortality, and cardiovascular disease. New England Journal of Medicine 315 1519-1524. (doi:10.1056/ NEJM198612113152405)

Bastianetto S, Ramassamy C, Poirier J \& Quirion R 1999 Dehydroepiandrosterone (DHEA) protects hippocampal cells from oxidative stressinduced damage. Molecular Brain Research 66 35-41. (doi:10.1016/ S0169-328X(99)00002-9)

Bigos K, Folan M, Jones M, Haas G, Kroboth F \& Kroboth P 2009 Dysregulation of neurosteroids in obsessive compulsive disorder. Journal of Psychiatric Research 43 442-445. (doi:10.1016/j.jpsychires. 2008.04.007)

Black MD, Selk DE, Hitchcock J, Wettstein JG \& Sorensen SM 1999 On the effect of neonatal nitric oxide synthase inhibition in rats: a potential neurodevelopmental model of schizophrenia. Neuropharmacology 38 1299-1306. (doi:10.1016/S0028-3908(99)00041-6)

Bocking AD, McMillen IC, Harding R \& Thorburn GD 1986 Effect of reduced uterine blood-flow on fetal and maternal cortisol. Journal of Developmental Physiology 8 237-245.

Brosnan PG 2001 The hypothalamic pituitary axis in the fetus and newborn. Seminars in Perinatology 25 371-384. (doi:10.1053/sper.2001. 29038)

Brunjes PC, Korol DL \& Stern KG 1989 Prenatal neurogenesis in the telencephalon of the precocial mouse Acomys cahirinus. Neuroscience Letters 107 114-119. (doi:10.1016/0304-3940(89)90801-X)

Cadet R, Pradier P, Dalle M \& Delost P 1986 Effects of prenatal maternal stress on the pituitary adrenocortical reactivity in guinea-pig pups. Journal of Developmental Physiology 8467.

Cardounel A, Regelson W \& Kalimi M 1999 Dehydroepiandrosterone protects hippocampal neurons against neurotoxin-induced cell death mechanism of action. Proceedings of the Society for Experimental Biology and Medicine 222 145-149. (doi:10.1046/j.1525-1373.1999.d01-124.x)

Carlström K, Pousette Å, Stege R \& Lindholm A 1990 Serum hormone levels in men with end stage renal disease. Scandinavian Journal of Urology and Nephrology 24 75-80. (doi:10.3109/00365599009180364)

Clark BJ, Wells J, King SR \& Stocco DM 1994 The purification, cloning, and expression of a novel luteinizing hormone-induced mitochondrial protein in MA-10 mouse Leydig tumor cells. Characterization of the steroidogenic acute regulatory protein (StAR). Journal of Biological Chemistry 269 28314-28322.

Compagnone NA \& Mellon SH 1998 Dehydroepiandrosterone: a potential signalling molecule for neocortical organization during development. PNAS 95 4678-4683. (doi:10.1073/pnas.95.8.4678)

Cotter D \& Pariante CM 2002 Stress and the progression of the developmental hypothesis of schizophrenia. British Journal of Psychiatry 181 363-365. (doi:10.1192/bjp.181.5.363)

Dickinson H \& Walker D 2007a Maternal dexamethasone treatment at midgestation reduces nephron number and alters renal gene expression in the fetal spiny mouse. American Journal of Physiololgy. Regulatory, Integrative and Comparative Physiology 292 R453-R461. (doi:10.1152/ ajpregu.00481.2006)

Dickinson H \& Walker D 2007b Managing a colony of spiny mice (Acomys cahirinus) for perinatal research. ANZCART News 20 4-11.

Dickinson H, Walker DW, Wintour EM \& Moritz K 2007 Maternal dexamethasone treatment at midgestation reduces nephron number and alters renal gene expression in the fetal spiny mouse. American Journal of Physiololgy. Regulatory, Integrative and Comparative Physiology 292 R453-R461. (doi:10.1152/ajpregu.00481.2006)

Dolecek R 1989 Endocrine changes after burn trauma - a review. Keio Journal of Medicine 38 262. (doi:10.2302/kjm.38.262)

Goodyer I, Herbert J \& Altham P 1998 Adrenal steroid secretion and major depression in 8-to 16-year-olds, III. Influence of cortisol/DHEA ratio at presentation on subsequent rates of disappointing life events and 
persistent major depression. Psychological Medicine 28 265-273. (doi:10.1017/S0033291797006314)

Goodyer I, Park R, Netherton C \& Herbert J 2001 Possible role of cortisol and dehydroepiandrosterone in human development and psychopathology. British Journal of Psychiatry 179 243-249. (doi:10.1192/bjp. 179.3.243)

Gordon CM, Grace E, Jean Emans S, Goodman E, Crawford MH \& Leboff MS 1999 Changes in bone turnover markers and menstrual function after short-term oral DHEA in young women with anorexia nervosa. Journal of Bone and Mineral Research 14 136-145. (doi:10.1359/jbmr. 1999.14.1.136)

Hammen C, Adrian C, Gordon D, Burge D, Jaenicke C \& Hiroto D 1987 Children of depressed mothers: maternal strain and symptom predictors of dysfunction. Journal of Abnormal Psychology 96190. (doi:10.1037/0021-843X.96.3.190)

Harris DS, Wolkowitz OM \& Reus VI 2001 Movement disorder, memory, psychiatric symptoms and serum DHEA levels in schizophrenic and schizoaffective patients. World Journal of Biological Psychiatry 2 99-102. (doi:10.3109/15622970109027500)

Harvey S, Merry B \& Phillips J 1980 Influence of stress on the secretion of corticosterone in the duck (Anas platyrhynchos). Journal of Endocrinology 87 161-171. (doi:10.1677/joe.0.0870161)

Hayashi A, Nagaoka M, Yamada K, Ichitani Y, Miake Y \& Okado N 1998 Maternal stress induces synaptic loss and developmental disabilities of offspring. International Journal of Developmental Neuroscience 16 209-216. (doi:10.1016/S0736-5748(98)00028-8)

Herbert J 1998 Neurosteroids, brain damage, and mental illness. Experimental Gerontology 33 713-727. (doi:10.1016/S0531-5565(98) 00039-4)

Hirsch A, Meimaridou E, Fernandez-Cancio M, Pandey AV, Clemente M, Audi L, Clark AJ \& Fluck CE 2011 Loss of the C terminus of melanocortin receptor 2 (MC2R) results in impaired cell surface expression and ACTH insensitivity. Journal of Clinical Endocrinology and Metabolism 96 E65-E72. (doi:10.1210/jc.2010-1056)

Holness MJ \& Sugden MC 2001 Dexamethasone during late gestation exacerbates peripheral insulin resistance and selectively targets glucosesensitive functions in $\beta$ cell and liver. Endocrinology 142 3742-3748.

Holson R, Gough B, Sullivan P, Badger T \& Sheehan D 1995 Prenatal dexamethasone or stress but not ACTH or corticosterone alter sexual behavior in male rats. Neurotoxicology and Teratology 17 393-401. (doi:10.1016/0892-0362(94)00074-N)

Huhman KL, Moore TO, Ferris CF, Mougey EH \& Meyerhoff JL 1991 Acute and repeated exposure to social conflict in male golden hamsters: increases in plasma POMC-peptides and cortisol and decreases in plasma testosterone. Hormones and Behavior 25 206-216. (doi:10.1016/ 0018-506X(91)90051-I)

Iacono W \& Beiser M 1992 Are males more likely than females to develop schizophrenia? American Journal of Psychiatry 149 1070-1074.

Ishimura K \& Fujita H 1997 Light and electron microscopic immunohistochemistry of the localization of adrenal steroidogenic enzymes. Microscopy Research and Technique 36 445-453. (doi:10.1002/ (SICI)1097-0029(19970315)36:6 < 445::AID-JEMT2>3.0.CO;2-H)

Jarvis S, Moinard C, Robson SK, Baxter E, Ormandy E, Douglas AJ, Seckl JR, Russell JA \& Lawrence AB 2006 Programming the offspring of the pig by prenatal social stress: neuroendocrine activity and behaviour. Hormones and Behavior 49 68-80. (doi:10.1016/j.yhbeh.2005.05.004)

Johnston AL \& File SE 1991 Sex differences in animal tests of anxiety. Physiology \& Behavior 49 245-250. (doi:10.1016/0031-9384(91) 90039-Q)

Kalimi M, Shafagoj Y, Loria R, Padgett D \& Regelson W 1994 Antiglucocorticoid effects of dehydroepiandrosterone (DHEA). Molecular and Cellular Biochemistry 131 99-104. (doi:10.1007/BF00925945)

Kapoor A, Dunn E, Kostaki A, Andrews MH \& Matthews SG 2006 Fetal programming of hypothalamo-pituitary-adrenal function: prenatal stress and glucocorticoids. Journal of Physiology 572 31-44.

http://joe.endocrinology-journals.org DOI: $10.1530 / J O E-13-0514$
() 2014 Society for Endocrinology Printed in Great Britain
Katagiri M, Kagawa N \& Waterman M 1995 The role of cytochrome b5 in the biosynthesis of androgens by human P450c17. Archives of Biochemistry and Biophysics 317 343-347. (doi:10.1006/abbi.1995.1173)

Khorram N, Magee T, Desai M, Ross M \& Khorram O 2008 Maternal undernutrition influences offspring adrenal expression of steroidogenic enzymes in a gender specific manner. Reproductive Sciences 15766.

Khorram NM, Magee TR, Wang C, Desai M, Ross M \& Khorram O 2011 Maternal undernutrition programs offspring adrenal expression of steroidogenic enzymes. Reproductive Sciences 18 931-940. (doi:10.1177/ 1933719111404613)

Kimonides VG, Khatibi NH, Svendsen CN, Sofroniew MV \& Herbert J 1998 Dehydroepiandrosterone (DHEA) and DHEA-sulfate (DHEAS) protect hippocampal neurons against excitatory amino acid-induced neurotoxicity. PNAS 95 1852-1857. (doi:10.1073/pnas.95.4.1852)

Kimonides VG, Spillantini MG, Sofroniew MV, Fawcett JW \& Herbert J 1999 Dehydroepiandrosterone antagonizes the neurotoxic effects of corticosterone and translocation of stress-activated protein kinase 3 in hippocampal primary cultures. Neuroscience 89 429-436. (doi:10.1016/ S0306-4522(98)00347-9)

Kishimoto J, Tsuchiya T, Emson PC \& Nakayama Y 1996 Immobilizationinduced stress activates neuronal nitric oxide synthase (nNOS) mRNA and protein in hypothalamic-pituitary-adrenal axis in rats. Brain Research 720 159-171. (doi:10.1016/0006-8993(96)00101-1)

Kostic T, Andric S, Maric D, Stojilkovic S \& Kovacevic R 1999 Involvement of inducible nitric oxide synthase in stress-impaired testicular steroidogenesis. Journal of Endocrinology 163 409-416. (doi:10.1677/joe. 0.1630409 )

Kurata K, Takebayashi M, Morinobu S \& Yamawaki S $2004 \beta$-Estradiol, dehydroepiandrosterone, and dehydroepiandrosterone sulfate protect against $N$-methyl-D-aspartate-induced neurotoxicity in rat hippocampal neurons by different mechanisms. Journal of Pharmacology and Experimental Therapeutics 311 237-245. (doi:10.1124/jpet.104.067629)

Labrie F, Luu-The V, Labrie C \& Simard J 2001 DHEA and its transformation into androgens and estrogens in peripheral target tissues: intracrinology. Frontiers in Neuroendocrinology 22 185-212. (doi:10.1006/frne. 2001.0216)

Lamers WH, Mooren PG, Griep H, Endert E, Degenhart HJ \& Charles R 1986 Hormones in perinatal rat and spiny mouse - relation to altricial and precocial timing of birth. American Journal of Physiology 251 E78-E85.

Lammers C-H, Garcia-Borreguero D, Schmider J, Gotthardt U, Dettling M, Holsboer F \& Heuser IJ 1995 Combined dexamethasone/corticotropinreleasing hormone test in patients with schizophrenia and in normal controls: II. Biological Psychiatry 38 803-807. (doi:10.1016/0006-3223 (95)00065-8)

Larsson HJ, Eaton WW, Madsen KM, Vestergaard M, Olesen AV, Agerbo E, Schendel D, Thorsen P \& Mortensen PB 2005 Risk factors for autism: perinatal factors, parental psychiatric history, and socioeconomic status. American Journal of Epidemiology 161 916-925. (doi:10.1093/aje/ kwi123)

Lee-Robichaud P, Wright JN, Akhtar ME \& Akhtar M 1995 Modulation of the activity of human $17 \alpha$-hydroxylase-17,20-lyase (CYP17) by cytochrome b5: endocrinological and mechanistic implications. Biochemical Journal 308 901-908.

Lephart ED, Baxter CR \& Parker CR 1987 Effect of burn trauma on adrenal and testicular steroid hormone production. Journal of Clinical Endocrinology and Metabolism 64 842-848. (doi:10.1210/jcem-64-4-842)

Lindsay RS, Lindsay RM, Edwards CR \& Seckl JR 1996 Inhibition of $11 \beta$-hydroxysteroid dehydrogenase in pregnant rats and the programming of blood pressure in the offspring. Hypertension 27 1200-1204. (doi:10.1161/01.HYP.27.6.1200)

Lingas RI \& Matthews SG 2001 A short period of maternal nutrient restriction in late gestation modifies pituitary-adrenal function in adult guinea pig offspring. Neuroendocrinology 73 302-311. (doi:10.1159/ 000054647)

Mapes S, Corbin CJ, Tarantal A \& Conley A 1999 The primate adrenal zona reticularis is defined by expression of cytochrome 
b5,17 $\alpha$-hydroxylase/17,20-lyase cytochrome P450 (P450c17) and NADPH-cytochrome P450 reductase (reductase) but not 3ß-hydroxysteroid dehydrogenase/ $\Delta 5-4$ isomerase (3ß-HSD). Journal of Clinical Endocrinology and Metabolism 84 3382-3385.

Matsumoto K, Takeyasu K, Mizutani S, Hamanaka Y \& Uozumi T 1970 Plasma testosterone levels following surgical stress in male patients. Acta Endocrinologica 65 11-17.

Mednick SA, Machon RA, Huttunen MO \& Bonett D 1988 Adult schizophrenia following prenatal exposure to an influenza epidemic. Archives of General Psychiatry 45 189-192. (doi:10.1001/archpsyc.1988. 01800260109013)

di Michele F, Caltagirone C, Bonaviri G, Romeo E \& Spalletta G 2005 Plasma dehydroepiandrosterone levels are strongly increased in schizophrenia. Journal of Psychiatric Research 39 267-273. (doi:10.1016/ j.jpsychires.2004.08.005)

Miller WL \& Auchus RJ 2011 The molecular biology, biochemistry, and physiology of human steroidogenesis and its disorders. Endocrine Reviews 32 81-151. (doi:10.1210/er.2010-0013)

Moore MC, Thompson CW \& Marler CA 1991 Reciprocal changes in corticosterone and testosterone levels following acute and chronic handling stress in the tree lizard, Urosaurus ornatus. General and Comparative Endocrinology 81 217-226. (doi:10.1016/0016-6480(91) 90006-R)

van Niekerk JK, Huppert FA \& Herbert J 2001 Salivary cortisol and DHEA: association with measures of cognition and well-being in normal older men, and effects of three months of DHEA supplementation. Psychoneuroendocrinology 26 591. (doi:10.1016/S0306-4530(01) 00014-2)

Oades RD \& Schepker R 1994 Serum gonadal-steroid hormones in young schizophrenic-patients. Psychoneuroendocrinology 19 373-385. (doi:10.1016/0306-4530(94)90017-5)

Oberbeck R \& Kobbe P 2010 Dehydroepiandrosterone (DHEA): a steroid with multiple effects. Is there any possible option in the treatment of critical illness? Current Medicinal Chemistry 17 1039-1047. (doi:10.2174/092986710790820570)

O'Regan D, Kenyon C, Seckl J \& Holmes M 2004 Glucocorticoid exposure in late gestation in the rat permanently programs gender-specific differences in adult cardiovascular and metabolic physiology. American Journal of Physiology. Endocrinology and Metabolism 287 E863-E870. (doi:10.1152/ajpendo.00137.2004)

Pomerantz DK \& Pitelka V 1998 Nitric oxide is a mediator of the inhibitory effect of activated macrophages on production of androgen by the Leydig cell of the mouse. Endocrinology 139 922-931.

Quaroni L, Reglinski J, Wolf R \& Ewen Smith W 1996 Interaction of nitrogen monoxide with cytochrome P-450 monitored by surfaceenhanced resonance Raman scattering. Biochimica et Biophysica Acta 1296 5-8. (doi:10.1016/0167-4838(96)00097-0)

Quinn TA, Ratnayake U, Dickinson H, Nguyen TH, McIntosh M, Castillo-Melendez M, Conley AJ \& Walker DW 2013 Ontogeny of the adrenal gland in the spiny mouse, with particular reference to production of the steroids cortisol and dehydroepiandrosterone. Endocrinology 2525.

Rainey WE, Carr BR, Sasano H, Suzuki T \& Mason JI 2002 Dissecting human adrenal androgen production. Trends in Endocrinology and Metabolism 13 234-239. (doi:10.1016/S1043-2760(02)00609-4)

Retana-Márquez S, Bonilla-Jaime H, Vázquez-Palacios G, Martínez-García R \& Velázquez-Moctezuma J 2003 Changes in masculine sexual behavior, corticosterone and testosterone in response to acute and chronic stress in male rats. Hormones and Behavior $\mathbf{4 4} 327-337$. (doi:10.1016/j.yhbeh. 2003.04.001)
Ritsner M, Maayan R, Gibel A, Strous RD, Modai I \& Weizman A 2004 Elevation of the cortisol/dehydroepiandrosterone ratio in schizophrenia patients. European Neuropsychopharmacology 14 267-273. (doi:10.1016/j.euroneuro.2003.09.003)

Ryabinin AE, Wang Y-M \& Finn DA 1999 Different levels of fos immunoreactivity after repeated handling and injection stress in two inbred strains of mice. Pharmacology, Biochemistry, and Behavior 63 143-151. (doi:10.1016/S0091-3057(98)00239-1)

Ryan MCM, Sharifi N \& Condren R 2004 Evidence of basal pituitaryadrenal overactivity in first episode, drug naïve patients with schizophrenia. Psychoneuroendocrinology 29 1065-1070. (doi:10.1016/ j.psyneuen.2003.08.011)

Sloboda D, Moss T, Gurrin L, Newnham J \& Challis J 2002 The effect of prenatal betamethasone administration on postnatal ovine hypothalamic-pituitary-adrenal function. Journal of Endocrinology 172 71-81. (doi:10.1677/joe.0.1720071)

Smith JT \& Waddell BJ 2000 Increased fetal glucocorticoid exposure delays puberty onset in postnatal life. Endocrinology 141 2422-2428. (doi:10.1210/endo.141.7.7541)

Snyder GD, Holmes RW, Bates JN \& Van Voorhis BJ 1996 Nitric oxide inhibits aromatase activity: mechanisms of action. Journal of Steroid Biochemistsry and Molecular Biology 58 63-69. (doi:10.1016/0960-0760(96)00008-8)

Tagawa N, Katagiri M \& Kobayashi Y 2006 Developmental changes of serum steroids produced by cytochrome P450c17 in rat. Steroids $\mathbf{7 1}$ 165-170. (doi:10.1016/j.steroids.2005.09.006)

Van Weerden W, Bierings H, Van Steenbrugge G, De Jong F \& Schröder F 1992 Adrenal glands of mouse and rat do not synthesize androgens. Life Sciences 50 857-861. (doi:10.1016/0024-3205(92)90204-3)

Waddell BJ, Bollen M, Wyrwoll CS, Mori TA \& Mark PJ 2010 Developmental programming of adult adrenal structure and steroidogenesis: effects of fetal glucocorticoid excess and postnatal dietary omega-3 fatty acids. Journal of Endocrinology 205 171-178. (doi:10.1677/JOE-09-0459)

Walf AA \& Frye CA 2012 Gestational or acute restraint in adulthood reduces levels of $5 \alpha$-reduced testosterone metabolites in the hippocampus and produces behavioral inhibition of adult male rats. Frontiers in Cellular Neuroscience 6 40. (doi:10.3389/fncel.2012.00040)

Welberg LAM \& Seckl JR 2001 Prenatal stress, glucocorticoids and the programming of the brain. Journal of Neuroendocrinology 13 113-128. (doi:10.1111/j.1365-2826.2001.00601.x)

Wilder R 1996 Adrenal and gonadal steroid hormone deficiency in the pathogenesis of rheumatoid arthritis. Journal of Rheumatology. Supplement $\mathbf{4 4} 10$.

Wilson E, Rogler J \& Erb R 1979 Effect of sexual experience, location, malnutrition, and repeated sampling on concentrations of testosterone in blood plasma of Gallus domesticus roosters. Poultry Science $\mathbf{5 8}$ 178-186. (doi:10.3382/ps.0580178)

Wolkowitz OM \& Reus VI 2000 Neuropsychiatric effects of dehydroepiandrosterone (DHEA). In Dehydroepiandrosterone (DHEA): Biochemical, Physiological and Clinical Aspects, pp 271-298. Berlin, Germany: Walter De Gruyter.

Zarrow M, Philpott J \& Denenberg V 1970 Passage of 14C-4-corticosterone from the rat mother to the foetus and neonate. Nature 226 1058-1059. (doi:10.1038/2261058a0)

Zhu Z, Li X, Chen W, Zhao Y, Li H, Qing C, Jia N, Bai Z \& Liu J 2004 Prenatal stress causes gender?dependent neuronal loss and oxidative stress in rat hippocampus Journal of Neuroscience Research 78 837-844. (doi:10.1002/ jnr.20338)

Zwain IH \& Yen SSC 1999 Dehydroepiandrosterone: biosynthesis and metabolism in the brain. Endocrinology 140 880-887. (doi:10.1210/ endo.140.2.6528)

Received in final form 11 February 2014

Accepted 3 March 2014

Accepted Preprint published online 3 March 2014 http://joe.endocrinology-journals.org DOI: 10.1530/JOE-13-0514
(C) 2014 Society for Endocrinology Printed in Great Britain 